\title{
Curral de reses, curral de almas introdução à urbanização dos "Certoens" das capitanias do Norte (séculos XVII-XIX)
}

\author{
Esdras Arraes ${ }^{1}$
}

\begin{abstract}
Resumo
Analisar como ocorreu a paulatina estruturação das redes urbanas (eclesiástica e civil) dos sertões das capitanias do Norte é o objetivo deste ensaio. Com foco nas zonas interiorizadas dos atuais estados que compõem a região Nordeste do Brasil, propõe-se a descortinar a política de urbanização de Portugal através da institucionalização de núcleos urbanos, estrategicamente locados no território, para o favorecimento do Estado luso e Igreja Católica, unidos ao longo do colonialismo por acordos papais de benefícios mútuos. "Curral de reses" busca esclarecer como a pecuária extensiva constituiu o elemento principal para o povoamento e posse das terras sertanejas. Sem o gado não seria possível o surgimento do "curral de almas", isto é, de assentamentos humanos que viriam a configurar o sistema urbano dos sertões nordestinos.
\end{abstract}

\section{Palavras-chave}

Colonialismo, pecuária, rede urbana, sertão nordestino, urbanização.

Recebido em 10 de janeiro de 2013

Aprovado em 14 de março de 2013

ARRAES, Esdras. Curral de reses, curral de almas: introdução à urbanização dos 'Certoens' das capitanias do Norte (século XVII-XIX). Revista do Instituto de Estudo Brasileiros, Brasil, n. 58, p. 51-77, jun. 2014. DOI: http://dx.doi.org/10.11606/issn.2316-901X.v0i58p51-77

1 Universidade de São Paulo (USP, São Paulo, SP, Brasil). 


\title{
Cattle's Corral, Soul's Corral Introduction to Urbanization of the "Certoens" of the North Captaincies (17th -19 th centuries)
}

\author{
Esdras Arraes
}

\begin{abstract}
Analyze occurred as the gradual structuring of urban networks (civil and ecclesiastical) of the hinterlands of North captaincies is the purpose of this essay. Focusing on areas of current internalized states that comprise the Northeast region of Brazil, aims to uncover the urbanization policy of Portugal through the institutionalization of human settlements, strategically leased territory, for favoring the Portuguese State and the Catholic Church, the united over colonialism by papal agreements of mutual benefits. "Cattle corral" seeks to clarify how the ranching was the main element for settlement and land tenure hinterland. Without ranching would not be possible the emergence of the parishes, villages and cities, in other works, "Soul's corral".
\end{abstract}

\section{Keywords}

Colonialism, ranching, urban networks, northeastern backlands, urbanization. 


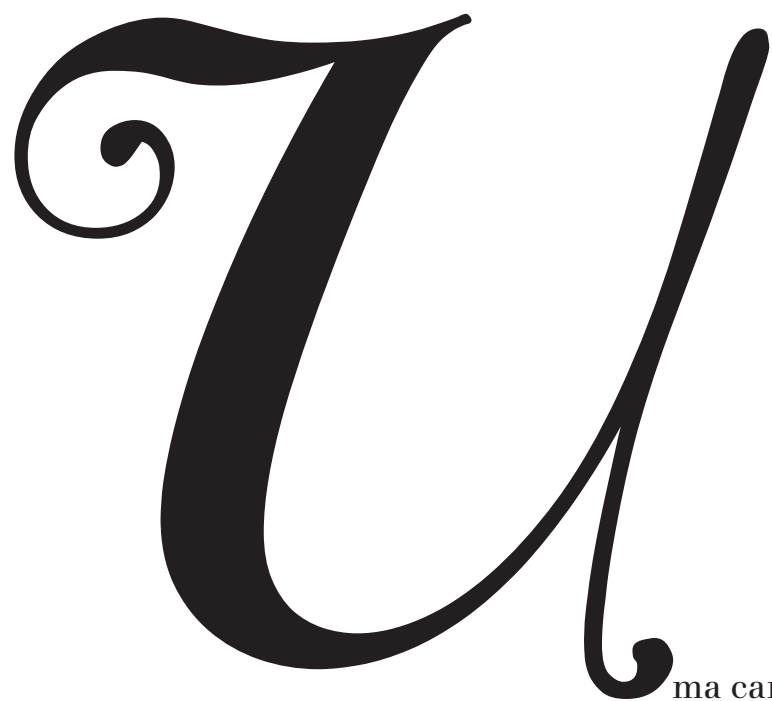

ma carta geográfica de Giacomo Gastaldi, possivelmente elaborada na segunda metade dos Quinhentos, representa o território interiorano da colônia americana de Portugal com a qualificação de “Terra non descoperta”. As dúvidas acerca daquela parte desconhecida seriam parcialmente desmistificadas a partir de notícias trazidas por sertanistas e aventureiros, que para lá rumaram em busca do El Dorado ou índios para escravização nas zonas litorâneas. Algumas dessas investidas foram animadas pelas autoridades coloniais, como aquela patrocinada por Thomé de Sousa, em 1551, em atenção às ordens de d. João III $^{2}$.

Dessa maneira, o incógnito e místico gravitaram o imaginário dos conquistadores, fazendo com que o português arranhasse a costa como caranguejo, segundo a metáfora de frei Vicente de Salvador ${ }^{3}$. Ao serem criados os primeiros assentamentos humanos da colônia, notamos sua prevalência junto à linha da praia: São Luís, Filipeia (atual João Pessoa), Olinda e Salvador foram as sentinelas dos confins dos domínios lusitanos, além de protagonizar as entradas de homens auxiliados por indígenas domesticados - os línguas - cujos fluxos tornaram-se basilares à estruturação de uma teia de caminhos a unir o interior ao mar, dando condições ao progressivo surgimento dos primeiros focos de povoamento dos "Certoens" das capitanias do Norte.

2 BANDEIRA, Luiz Alberto Moniz. Ofeudo: a Casa da Torre de Dias d'Ávila - da conquista dos sertões à independência do Brasil. Rio de Janeiro: Civilização Brasileira, 2000, p. 127.

3 SALVADOR, frei Vicente de. História do Brasil: 1500-1627. $7^{\text {a }}$ ed. São Paulo: Edusp, 1982 , p. $15^{2}$. 
Não bastava somente conhecer e devassar o território, seria necessário fixar o homem de facto ao chão, executar umas das primeiras prerrogativas registradas nos autos reais: povoar a terra e florescê-la com povoações para o beneficio comum dos povos. E foi a pecuária extensiva que agiu como leitmotiv na estruturação da rede urbana sertaneja. Graças ao gado, os sertões das capitanias que compuseram, grosso modo, o Nordeste colonial, entraram nos planos e estratégias geopolíticas da monarquia portuguesa.

\section{Curral de reses}

Algumas décadas antes do desenvolvimento do caminho real do gado ${ }^{4}$, que uniria, por terra, as urbes de São Luís do Maranhão e Salvador, um grupo de homens, associados e residentes no recôncavo da Bahia $^{5}$, solicitaram ao governo da capitania de Pernambuco, por volta de 1684, uma vasta sesmaria localizada entre o rio São Francisco e o atual estado do Piauí, para criar gados soltos, extensivamente. As reses logo se adaptaram ao lugar, enquanto não ocorressem os longos períodos de estiagem, provocando a redução de até $12,5 \%$ das boiadas criadas e tangidas para comercialização no litoral ${ }^{6}$. Sérgio Buarque de Holanda, por seu turno, listou dois fatores positivos ao povoamento do sertão: 0 relevo formado por peneplanícies e os barreiros salinos encontrados ao longo do médio rio São Francisco ${ }^{7}$.

Isto posto, o conhecimento e a efetiva ocupação da região foram os elementos que mais se beneficiaram da economia pastoril. De fato, a ocupação do interior nordestino foi determinada pela necessidade de prover a área açucareira de animais para o trabalho nos engenhos e

4 AHU_ACL_CU_o16, cx. 3, d. 217. As referências indicadas segundo a sigla AHU dizem respeito às fontes primárias manuscritas encontradas no Arquivo Histórico Ultramarino de Portugal, que foram digitalizadas pelo Projeto Resgate Barão do Rio Branco. Agradeço a Cátedra Jaime Cortesão por ter me concedido o acesso aos CD's do projeto.

5 Esses grandes possuidores de terras eram a família Dias D’Ávila (a Casa da Torre), os Guedes de Brito (Casa da Ponte), Francisco Barboza Leão, Bernardo Pereira Gago, Domingos Afonso Mafrense (alcunhado depois de Sertão), Francisco de Souza Fagundes, Bernardo Vieyra Ravasco. Ver AHU_ACL_CU_oog, cx. 33, d. 3343. Por questões de método de pesquisa, usamos os nomes dos atores seguindo a grafia encontrada nos manuscritos setecentistas.

6 BRAGA, Renato. Um capítulo esquecido da esconomia pastoril do Nordeste. Revista do Instituto do Ceará. Fortaleza, 1947, t. LXI, p. 149-152.

7 HOLANDA, Sérgio Buarque de. História da civilização brasileira. São Paulo: Difusão Europeia do Livro, 196o, v. II, t. I, p. 221. 
alimento para a população ali residente ${ }^{8}$. Por isso, Capistrano de Abreu apontou dois polos de arremetida para o hinterland: os sertões de dentro e de fora. O primeiro elaborado pelos baianos, percorrendo as margens dos rios Itapicuru, Rãs, Vaza-Barris, Sergipe, Real, São Francisco, Canindé e Piauí para atingir as áreas interioranas dos atuais estados da Bahia, Sergipe, Alagoas, Pernambuco, Ceará, Piauí e Maranhão ${ }^{9}$. O sertão de fora é obra pernambucana. Partindo de Olinda/Recife, os sertanistas seguiam paralelamente à linha da praia até atingir os sertões do Ceará, passando pelas capitanias da Paraíba e Rio Grande ${ }^{10}$.

Já no início do século XVIII, os "Certoens" do Norte eram percorridos por inúmeras boiadas e, portanto, tratava-se da especificidade econômica daquela parte da colônia. Tal realidade foi apontada pelo jesuíta Antonil, quando relatou a existência de oitocentos currais nas margens sanfranciscanas do lado pernambucano e quinhentos da parte baiana. Ou melhor,

assim como há currais nos territórios da Bahia e de Pernambuco, e de outras capitanias, de duzentas, trezentas, quatrocentas, quinhentas, oitocentas e mil cabeças, assim a fazenda a quem pertencem tantos currais que chegam a ter $6 \mathrm{mil}, 8 \mathrm{mil}, 10 \mathrm{mil}$, 15 mil e mais de 20 mil cabeças de gado, donde se tiram cada ano muitas boiadas, conforme os tempos são mais ou menos favoráveis à parição e multiplicação do mesmo gado, e aos pastos assim nos sítios como também nos caminhos. ${ }^{11}$

Currais e fazendas de gado entram, portanto, neste quebra-cabeça da posse e uso de terras sertanejas. A fundação de herdades e, a posteriori, de núcleos urbanos, cumpriram os ideais da política colonizadora de Portugal, principalmente a partir da última década dos Seiscentos, no reinado de d. Pedro II, quando a Coroa buscou conter os avanços fundiários dos mandatários do sertão:

8 ANDRADE, Manuel Correia de. O processo de ocupação do espaço regional do Nordeste. $2^{\mathrm{a}}$ ed. Recife: SUDENE, 1979.

9 ABREU, Capistrano de. Capítulos de história colonial, I5oo-I8oo. $7^{\text {a }}$ ed. São Paulo: Publifolha, 2000, p. 150-160.

10 ABREU, Capistrano de, op. cit., p. 150-16o.

11 ANTONIL, André João. Cultura e opulência do Brasil. $z^{\text {a }}$ ed. Belo Horizonte: Itatiaia/Edusp, 1982, p. 96. (Coleção Reconquista do Brasil). 
ainda poderá ser maiz util com o intento q' tem de povoarem aquellas terraz, reduzindoas a Collonias, e Povoaçoens, sendo este o meyo não só de se segurarem aquelles Certoens com estas defenças, mas tambem o de poder lucrar grandez conviniençias a fazenda de V. Mag. ${ }^{\text {de }}$ nos dizimos que se podem tirar da Cultura dellaz que pella sua excellençia, e fertilidade prometem a mayor abundançia de fruitos ${ }^{12}$

Analisando certos manuscritos, com datas entre 1699-1755, perceberemos que o esforço da Metrópole lusitana - com o intuito de diminuir o poderio dos grandes fazendeiros e distribuir equitativamente as sesmarias, segundo a dimensão legal pré-determinada pelas Ordenações do Reino - alcançou consideráveis resultados. Através da carta régia de 20 de janeiro de 1699, d. Pedro II (ao saber do parco povoamento do território) ordenou que sesmarias devolutas fossem concedidas aos desejosos de cultivá-las, mediante o pagamento do foro ${ }^{13}$. Além do mais, surge, no intervalo de tempo citado, um grande número de fazendas de criar que salpicaram o território, muitas delas fundadas ao longo de caminhos terrestres, outras nas ribeiras dos rios.

Sobre esses aspectos, um bom exemplo a ser mencionado é o caso da capitania de São José do Piauí. Em 1697, o padre Miguel de Carvalho foi encaminhado pelo bispo de Pernambuco, d. Francisco de Lima, ao sertão de sua diocese, para averiguar a região a fim de instalar duas novas freguesias, derivadas da imensa paróquia de Cabrobó, cuja

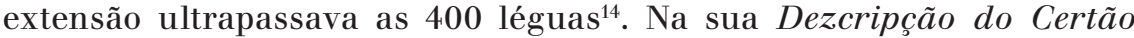
do Peauhy remetido ao Ilmo. e Rm. Sr. Frei Francisco de Lima, o cura relacionou 129 fazendas de gado, onde residiam 441 moradores entre brancos, índios, negros e mestiços ${ }^{15}$. Já em 1772, ao observamos o relatório do ouvidor Antônio José de Morais Durão, o Piauí esteve povoado com 579 estâncias de gado, distribuídas nos termos da cidade de Oeiras e das vilas de Parnaguá, Jerumenha, Valença do Piauí, Marvão, Campo Maior e Parnaíba ${ }^{16}$.

Contemporâneo aos dados informados pelo ouvidor Durão foi o censo desenvolvido, em 1774, pelo governador de Pernambuco, Jozé Cezar de Menezes. A autoridade pernambucana nos deixa a par da existência de 2.363 fazendas de gado erguidas por todo o território da

12 ENNES, Ernesto. As guerras nos Palmares. Rio de Janeiro: Cia. Editora Nacional, 1938, p. 349-350.

13 AHU_ACL_CU_015, cx.18, d. 1771.

14 AHU_ACL_CU_015, cx.17, d. 1732.

15 ENNES, Ernesto. As guerras nos Palmares, op. cit., p. 370-387.

16 AHU_ACL_CU_oı6, cx. 12, d. 684. 
capitania e suas sufragâneas (Ceará, Rio Grande, Paraíba e Alagoas) ${ }^{17}$. Ao analisarmos a Tabela 01, consideramos que teve razão o capitão-mor da Paraíba, João da Maia da Gama, ao declarar a d. João V, que "hachase os certoens desta capitania muy povoada de [...] fazendas, e gados". ${ }^{18}$

\begin{tabular}{|c|c|}
\hline \multicolumn{2}{|c|}{ FAZENDAS DA CAPITANIA DE PERNAMBUCO E SUAS ANEXAS, 1774} \\
\hline \multicolumn{2}{|c|}{ CAPITANIA DO CEARÁ GRANDE } \\
\hline Ribeira & Fazendas \\
\hline Ribeira do Ceará & 93 \\
\hline Ribeira do Aracaru & 325 \\
\hline Ribeira do Jaguaribe & 240 \\
\hline Ribeira do Icó & 314 \\
\hline TOTAL & 962 \\
\hline \multicolumn{2}{|c|}{ CAPITANIA DO RIO GRANDE DO NORTE } \\
\hline Ribeira & Fazendas \\
\hline Ribeira do Norte & 28 \\
\hline Ribeira do Assu & 96 \\
\hline Ribeira do Apodi & 54 \\
\hline Ribeira do Seridó & 70 \\
\hline Ribeira so sul & 35 \\
\hline TOTAL & 283 \\
\hline \multicolumn{2}{|c|}{ CAPITANIA DA PARAÍBA } \\
\hline Freguesias & Fazendas \\
\hline Taipu & 99 \\
\hline Pilar & 01 \\
\hline Iacocá & - \\
\hline Alandra & - \\
\hline Barra da Traição & - \\
\hline Cariris & 87 \\
\hline Mamanguape & 75 \\
\hline Pombal & 560 \\
\hline Campina & 47 \\
\hline
\end{tabular}

17 Idéia da população da Capitania de Pernambuco, e das suas annexas, extenção das suas Costas, Rios, e Povoaçoens notáveis, Agricultura, numero de Engenhos, Contractos, e Rendimentos Reaes, augmento que este tem sido \& desde o anno de $\mathbf{1 7 7 4}$, em que tomou posse do Governo das mesmas Capitanias o Governador e Capitam General Jozé Cezar de Menezes. Annaes da Bibliotheca Nacional do Rio de Janeiro, Rio de Janeiro, 1918, v. XL.

18 AHU_ACL_CU_o14, cx. 4, d. 310 . 


\begin{tabular}{|c|c|}
\hline TOTAL & 869 \\
\hline \multicolumn{2}{|c|}{ CAPITANIA DE PERNAMBUCO } \\
\hline Freguesias & Fazendas \\
\hline Taquara & - \\
\hline Alhandra & - \\
\hline Goyana & - \\
\hline També & - \\
\hline Tejucopapo & - \\
\hline Itamaracá & - \\
\hline Iguaraçu & - \\
\hline Limoeiro & - \\
\hline Tracunhaém & - \\
\hline Bom Jardim & - \\
\hline Maranguape & - \\
\hline São Pedro Mártir & - \\
\hline Sé de Olinda & - \\
\hline Vargem & - \\
\hline Jaboatão & - \\
\hline São Lourenço & - \\
\hline Luz & - \\
\hline Santo Antão & - \\
\hline Ararobá & 25 \\
\hline Simbres & - \\
\hline Águas Belas & - \\
\hline Cabrobó & 60 \\
\hline Bezerros & 88 \\
\hline Tacaratu & 60 \\
\hline Pilão Arcado & 35 \\
\hline São Frei Pedro Gonçalvez & - \\
\hline Moribeca & - \\
\hline Cabo & 01 \\
\hline Iројuса & 01 \\
\hline Escada & - \\
\hline Porto Calvo & - \\
\hline Camaragibe & - \\
\hline São Bento & - \\
\hline Unna & - \\
\hline Meirim & - \\
\hline Alagoas & - \\
\hline
\end{tabular}




\begin{tabular}{|c|c|}
\hline São Miguel & 32 \\
\hline Alagia do Norte & - \\
\hline Atalaia & 08 \\
\hline Poxim & 14 \\
\hline Penedo & 80 \\
\hline Porto Real & - \\
\hline Nossa senhora do Ó & 114 \\
\hline São Francisco da Barra do Rio Grande & Sem informação \\
\hline São Romão & Sem informação \\
\hline Aldeia de índios da Assumpção & Sem informação \\
\hline Vila de Santa Maria & Sem informação \\
\hline TOTAL & $\mathbf{5 1 8}$ \\
\hline
\end{tabular}

Tabela o1: Fazendas da Capitania de Pernambuco, 1774. Elaborada pelo autor segundo informações da "Idéia da população da Capitania de Pernambuco, e das suas annexas...”. In: Annaes da Bibliotheca Nacional do Rio de Janeiro. Ano 1918, v. XL. p. 5-116.

O predomínio da pecuária abrangeu os sertões de todas as capitanias que compuseram o Nordeste colonial, se assim o podemos classificar. No Piauí, “o principal rendimento da Fazenda Real [...] consiste nos dízimos dos gados vacuns e cavallares, genero cujo consumo sendo dependente da indigência em que estavão as capitanias circunvezinhas". ${ }^{19}$ Semelhante a situação do Ceará, como expôs o Conselho Ultramarino:

neste país tão vasto estando hoje povoado porque só a Ribeira do Jagoaribe estão mais de tresentas rossas e currais (...) e tanta gente q' cada ves se vay augmentando mas em razão dos grandes lucros que se tirão dos muitos bois e cavallos que se crião e mandão para as Minnas ${ }^{20}$

"Os bens dos sertanejos potiguares, identificados pelos edis da câmara de Natal, eram 'gado vacuns q' se crião nestes Certoens”. ${ }^{21}$ Referindo-se à freguesia de Bezerros, locada na capitania de Pernambuco, Jozé Cezar de Menezes mencionou que os moradores da paróquia vivem "de crear gados, outros de alguma lavoura que plantão nos brejos,

19 AHU_ACL_CU_o16, cx.11, d. 633 .

20 AHU_ACL_CU_CEARÁ, cx. 1, d. 67.

21 AHU_ACL_CU_o18, cx. 2, d. 140 . 
e de curtir couros e sollas; a conduta [sic.] destes gados he para a cidade da Bahia, onde fica mais proximo". ${ }^{22}$

Luís Vilhena informou, em 1802, ao príncipe regente, d. João VI, que para o termo da vila de Penedo (AL) transitavam gado, "de que seo destricto ha de duzentas a cincoenta fazendas, entre grandes $\mathrm{e}$ pequenas". ${ }^{23}$ Para Salvador, vinham manadas da vila da Jacobina, pois "abundão os dittos sertões de gado, cujas estradas livres de gentio e beneficiados podem fazer hum extenso commercio com a comarca e com a capital, sendo aquella tão desprovida de gado". ${ }^{24}$

Em Pastos Bons, região meridional do Maranhão, devido à demanda de boas pastagens e água de rios perenes, o major Francisco de Paula Ribeiro comentou:

A natureza de uns e outros terrenos, excessivamente prodiga na sua vegetação, é que talvez adquiriu para todo este districto o nome de Pastos Bons! Os seus campos nutridores, o seu ar commodo, preciosas águas, grande fertilidade seguida ao mais pequeno cultivo e a sua nunca interrompida verdura, são circumstancias que fazem com que este paiz seja o mais abundante e delicioso: por isso mesmo é que elle chama dos sertões das outras capitanias confinantes os negociantes de gado, que d'alli transportam para manutenção e povoação dos seus infecundos campos e criação das vacas e novilhas ${ }^{25}$

É interessante destacar que as transações comerciais provenientes da pecuária orbitaram em outra escala: abrangeram o ultramar, aportando no Reino. Em Pernambuco e Paraíba, o segundo produto que mais pesou na balança das exportações eram derivados do boi. Em carta aos representantes do Estado e Negócios Ultramarinos, os edis da câmara de Olinda atestaram que os "donativos com que aqueles povos servem de

22 Annaes da Bibliotheca Nacional do Rio de Janeiro. Rio de Janeiro, 1918, v. XL, p. 38.

23 VILHENA, Luiz dos Santos. Recopilação de noticias soteropolitanas e brasílicas, Salvador, 1802, v. 1, p. 10 s. Manuscrito disponível em <http://www.bndigital.bn.br>. Acesso em set. 2013 .

24. Annaes da Bibliotheca Nacional do Rio de Janeiro. Rio de Janeiro, 1912, v. XXXIV, p. 112.

25 Descripção do território de Pastos Bons, nos sertões do Maranhão. Propriedades dos seus terrenos, suas producções, caracter dos seus habitantes colonos, e estados actual dos seus estabelecimentos: pelo major Francisco de Paula Ribeiro (1819). Revista do Instituto Histórico e Geográfico Brasileiro. Rio de Janeiro, 1849, p. 44. 
presente a Vossa Magestade que seja servido ordenar que se satisfaçam gêneros como açúcar e sola que são os que servem ao comércio". ${ }^{26}$ Do porto do Recife saíam para Portugal entre sete a oito embarcações por ano, carregadas de couro ${ }^{27}$.

No porto da vila de Aracati, o frei capuchinho, Aníbal de Gênova, em sua missão ambulante de 1762, notou o comércio de carne e couro daquele núcleo urbano. Ali, o religioso testemunhou que era "lugar de muito comércio. Consistia na sua principal riqueza na criação, embarcando anualmente grandes boiadas para Pernambuco. Via-se também frequentado por muitos marchantes baianos". ${ }^{28} \mathrm{O}$ capuchinho ainda cita que o porto de Aracati interagiu com outros centros da colônia (Recife, Salvador e Rio de Janeiro) e da América. A cidade de Buenos Aires, por exemplo, esteve subsidiada de produtos da pecuária nordestina ${ }^{29}$.

O criatório começou a declinar no fim do século XVIII e início dos Oitocentos. O primeiro motivo dizia respeito às secas apelidadas de três setes $(1777,1778,1779)$ responsável pela mortandade do gado. O segundo justifica-se pela ascensão, ante o mercado nacional e, depois, internacional, das charqueadas do Sul, cuja fórmula de produção da carne, segundo Valdelice Girão, foi emigrada do Ceará com seus especialistas ${ }^{50}$. Vilhena presenciou esse câmbio de pólo monopolista:

Era muito considerável o commercio que esta Praça tinha com a Capitania do Ceará, e Parnahiba, em carnes salgadas, seccas, courama e algum algodão, este porém se transferio para o Rio Grande de S. Pedro do Sul, depois que as secas extremosas consumirão todos os gados naquellas paragens; de forma que por acaso apparece hoje na Bahia alguma pequena embarcação do Ceará, ou Parnahiba, com carne e couros; visto que em Pernambuco achão prompta sahida a todos os seus gêneros e effeitos ${ }^{31}$

O decréscimo econômico pode ser visto na ocupação dos habitantes da capitania da Paraíba do Norte em 1798, quando foram elencados

26 GOULART, José Alípio. Brasil do boi e do couro. 2 vol. (O couro). Rio de Janeiro: Edições GRD, 1966, p. 25.

27 VILHENA, Luiz dos Santos, op. cit., p. 26.

28 PRIMEIRO, P. Fr. Fidelis M. de. Capuchinhos em Terra de Santa Cruz nos séculos XVII, XVIII e XIX. São Paulo: Martins, 1942, p. 191.

29 Idem, ibidem.

zo GIRÃO, Valdelice. As charqueadas. Revista do Instituto do Ceará. Fortaleza, 1996, t. CX, p. 16o.

31 VILHENA, Luiz dos Santos, op. cit., p. 342. 
apenas 174 criadores de gado ${ }^{32}$. Diminuição da exportação também ocorreu nos sertões dos Pastos Bons (MA). Segundo o relatório do major Francisco de Paula Ribeiro, de 1815, a freguesia de São Bento dos Pastos Bons atrofiou sua negociação com a Bahia e São Luís, pela alta dos preços e pouca compra dos animais ${ }^{33}$.

Mesmo com a crise sofrida, as reses mobilizaram os funcionários da Coroa, as câmaras das vilas, autoridades religiosas, fazendeiros, roceiros, vaqueiros, tangedores, índios e escravos. Os fluxos do gado e sua participação na economia interna colonial romperam as fronteiras entre capitanias, deram uma nova territorialidade ao Brasil, extrapolando a virtualidade do Tratado de Tordesilhas ${ }^{34}$. Dentro dessa órbita comercial, política e social foi instituída, a priori, uma rede eclesiástica de aldeamentos missioneiros e freguesias, localizados estrategicamente no território e cumprindo funções hierárquicas definidas pela Igreja Católica e Estado português, umbilicalmente ligados por acordos de benefícios mútuos ${ }^{35}$. Em seguida, quando a criação de gado se estabelece no âmbito do mercado interno, a monarquia lusitana preocupou-se em implantar práticas urbanizadoras que incidiram sobre o espaço ${ }^{36}$, por isso, formou-se nos "Certoens" do Norte um sistema urbano composto por dezenas de vilas e uma cidade, criando estreitas relações entre o território e o ultramar.

\section{Curral de almas}

Na portada da igreja matriz da atual cidade de Oeiras do Piauí, edificada em 1733, nos deparamos com a frase em latim: Hoc est domus Domini $i^{37}$, que traduzida para o português teríamos: "esta é a casa do Senhor". ${ }^{38}$ Ao longo do colonialismo, os templos católicos agregaram ao seu redor, num processo lento, as moradias dos fiéis comprometidos com os ritos da cristandade. Por extensão, o pequeno assentamento humano

32 AHU_ACL_CU_o16, cx.14, d. 2510.

33 Revista do Instituto Histórico e Geográfico Brasileiro, op. cit., p. 51.

34. ARINOS, Afonso. Síntese da história econômica do Brasil. Salvador: UFBA, 1958, p. 56.

35 MARX, Murillo. Cidade no Brasil: terra de quem? São Paulo: Edusp/ Nobel, 1991, p. 11.

36 REIS FILHO, Nestor Goulart. Contribuição ao estudo da evolução urbana do Brasil: 1500-1720. São Paulo: Pioneira/ Edusp, 1968, p. 200.

37 A oração completa é Hoc est domus Domini firmiter Adificata Anno Domini I733.

38 CARVALHO Jr., Dagoberto Ferreira de. Passeio a Oeiras. $6^{\text {a }}$ ed. Teresina: Fundação Cultural do Piauí, 2010, p. 75-79. 
que se formava fazia parte da "casa do Senhor", a congregar os dispersos pelo sertão à "sombra da cruz".

Atualmente, muito se tem divulgado o papel da religião na estruturação da rede urbana brasileira. Murillo Marx foi um dos primeiros a debater o tema na academia ${ }^{39}$. Marx percebeu que a união entre Igreja Católica e Estado português teve séria repercussão sobre o chão e paisagem de nossos núcleos urbanos coloniais, desde os mais próximos da costa atlântica até aos mais interioranos. Dessa maneira, e seguindo os conceitos de Marx, consideraremos nesta parte, em linhas gerais, como as autoridades coloniais (civis e eclesiásticas), através de medidas bem orquestradas, estimularam a fixação do homem sertanejo e do nativo (os tapuias) em um sistema urbano com elementos posicionados estrategicamente no território.

Para concretizar seus ideais de conquista e assegurar as desconhecidas áreas interioranas, era dever da monarquia e, de reboque, dos seus funcionários eclesiásticos e civis "se empregar na conversam das Almas, [...], para augmentar a Religiam Catholica e dilatar a Doutrina Evangelica n'estas Conquista" ${ }^{40}$ Com efeito, a Coroa lusa patrocinou a fundação de aldeamentos missioneiros espalhados em pontos nevrálgicos do território sertanejo. É interessante destacar que, muitos desses lugares de índios foram instalados em zonas de intenso conflito fundiário, como as margens médias do rio São Francisco; no sertão do Assu da capitania do Rio Grande; na ribeira do rio Jaguaribe (Ceará) e no sertão baiano, nas proximidades da atual cidade de Jacobina. A busca pelo sossego, diante dos atritos elaborados entre nativos e colonizadores, e a dilatação dos confins dos domínios lusitanos estiveram, por assim dizer, no bojo do estabelecimento das reduções religiosas.

Entre as "religiões" destacaram-se os capuchinhos, jesuítas e oratorianos. Os oratorianos, também chamados de congregados ou recoletas, fundaram poucas reduções de silvícolas ${ }^{41}$, embora algumas tenham sido, já no século XVII, convertidas em paróquias e depois em

39 MARX, Murillo, op. cit.

40 Annaes da Bibliotheca Nacional do Rio de Janeiro. Informação geral da capitania de Pernambuco. (1906). Rio de Janeiro: Officinas de Artes Graphicas da Bibliotheca Nacional, 1908, v. XXVIII, p. 381.

41 A Junta das Missões, por volta de 1684, designou os padres do Oratório de São Felipe Nery para quatro reduções: Ipojuca, Carnijó, Limoeiro e Arorobá. Cf. AHU_ACL_ CU_o15, cx. 13, d. 1320. Em nossa dissertação de mestrado, defendida em 2012 na Faculdade de Arquitetura da Universidade de São Paulo, nos alongamos mais sobre a ação catequética dos oratorianos no sertão pernambucano. ARRAES, Damião Esdras Araújo. Curral de reses, curral de almas: urbanização do sertão nordestino entre os séculos XVII e XIX. 2012. 504 p. il. Dissertação (Mestrado em Arquitetura e 
vilas. O papel desses aldeamentos foi primordial ao programa expansionista das fronteiras coloniais, portanto, averiguar a precisa localização dessas comunidades indígenas e sua atuação dentro da conjuntura política de Portugal revelam interessantes pistas sobre a urbanização do interior das capitanias do Norte.

A atividade capuchinha iniciou em 1612 com a fundação da cidade de São Luís do Maranhão. Os frades franceses Ivo de Evreux, Claude D’abbeville, Arsensino de Paris e Ambrósio de Amiens doutrinaram os nativos residentes nas cercanias da ilha de São Luís ${ }^{42}$. Seu trabalho missioneiro fora muito bem relatado pelas narrativas de fr. Claude D'abbeville, que nos deixou sua História da missão dos padres capuchinhos na ilha do Maranhão e terras circunvizinhas ${ }^{43}$. No entanto, após a expulsão dos franceses pelos portugueses das terras maranhenses, em 1615, temos um enorme vácuo temporal acerca da propagação da fé pelos barbadinhos. Tal hiato seria parcialmente preenchido com a fundação, na vila do Recife, do hospício de Nossa Senhora da Penha de França. E de lá partiram, a partir de 1670, todos os seus missionários para o território administrado pelo então governo pernambucano ${ }^{44}$. Cerca de oito aldeamentos capuchinhos se estabeleceram nos sertões da Paraíba, Rio Grande do Norte e Ceará: Piancó, Miranda, Missão Velha, Missão Nova, Araripe, Apodi, Mipibu e Corima ${ }^{45}$.

No início do século XVIII, os capuchinhos locados na Prefeitura da Bahia foram designados essencialmente para as margens médias do rio São Francisco, lugar de intensas fainas entre grandes fazendeiros de gado e os indígenas locais. Para conter tais conflitos e os saques às herdades, a ideia de converter os silvícolas para o controle da área resultou na fundação de dez comunidades de índios: Irapoá, São Félix, Pambu, Vargem, Araxá, Rodelas, São Pedro, Vacapará, Paracatuba e Rio de Contas ${ }^{46}$. Dessas dezoito reduções administradas pelos barbadinhos três receberam o foro de vila após a homologação dos Diretórios dos Índios (1758), instrumento legal elaborado pela política reformista do marquês de Pombal: a missão do Miranda tornou-se, em 1764, a vila Real do Crato (CE); Mipibu recebeu o título de vila em 1761, passando a se chamar São José do Mipibu; e a

Urbanismo) - Faculdade de Arquitetura e Urbanismo, Universidade de São Paulo, 2012.

4.2 PRIMERIO, P. fr. Fidelis M. de., op. cit., 1942, p. 25.

43 CLAUDE, D’abbeville. História da missão dos padres capuchinhos na ilha do Ma ranhão e terras circunvizinhas. São Paulo: Martins, 1945.

44 PRIMERIO, P. fr. Fidelis M. de., op. cit., p. 56.

45 Idem, ibidem, p. 170-171.

46 Idem, ibidem, p. $15^{2}$. 
missão da capitania do Rio Grande do Norte, Apodi, converteu-se em Portalegre, criada em 1762.

A obra missioneira da Companhia de Jesus - largamente difundida por Serafim Leite em sua clássica obra História da Companhia de Jesus no Brasill ${ }^{47}$ - estendeu-se desde o Maranhão até a Bahia. Nos rincões do Nordeste, os inacianos fundaram aldeamentos missioneiros a favorecer, em meados dos Seiscentos, o conhecimento de áreas antes tidas como incógnitas. De maneira sucinta, as principais reduções jesuíticas que participaram na estruturação da rede civil de vilas, a nosso ver, foram: Aldeias Altas no Maranhão; a missão da Ibiapaba no Ceará, onde reuniu mais de cinco mil almas ${ }^{48}$; e as reduções da capitania da Bahia de Geru, Canabrava, Sacos dos Morcegos e Natuba, que receberam o status de vila, em 1758, e as novas designações, respectivamente, de Tomar do Geru, Pombal, Mirandela e Soure. Além dessas, outras comunidades de índios foram criadas na litigiosa área do médio rio São Francisco e nas proximidades do litoral.

Desses aglomerados sertanejos fundados pela Companhia de Jesus, sem dúvida devemos destacar a redução da Ibiapada, localizada na capitania do Ceará em uma área fronteiriça com a capitania do Piauí. As primeiras pregações do Evangelho ocorridas ali datam do final do século XVII. No entanto, foram frustradas, tanto pela falta e precariedade dos caminhos, como pela belicosidade dos índios: sabemos que o padre Francisco Pinto foi martirizado e morto pelos nativos da região. Entretanto, na opinião de Serafim Leite ${ }^{49}$, o período de estabilização da redução ocorreu a partir de 1691 (sob a tutela espiritual e temporal do padre Ascenso Gago) até 1759, ano da deportação dos jesuítas das colônias portuguesas. Ao longo dessas décadas, fora construída uma igreja resistente às intempéries do meio e planejado aglomerado humano muito semelhante a outras reduções da Companhia localizadas ao sul da América, como por exemplo, a conhecida missão de São Miguel, hoje patrimônio da humanidade.

Segundo as diretrizes de Gago, a missão da Ibiapaba adquiriu forma retangular, tendo ao centro uma grande praça para convívio, sociabilidade e doutrinação dos neófitos. Foram agrupadas distintas etnias em três bairros previamente zoneados: “o Principal D. Jacobo de Souza para a parte do nascente, com todos os seus vassalos; o principal

47 LEITE, Serafim. História da Companhia de Jesus no Brasil. 10 v. Rio de Janeiro: Instituto Nacional do Livro, 1938-1950.

48 AHU_ACL_CU_CEARÁ, cx. 6, d. 4,16.

49 LEITE, Serafim, op. cit., t. III, p. 3 . 
Salvador Saraiva, com os seus, para a parte do poente; e para a parte do sul, fechando a quadra da Aldeia, o Principal D. Simão Taminhombá, com seus vassalos". ${ }^{50}$

Em 1759, os inacianos foram considerados inimigos do Estado português e expulsos de suas colônias. A administração eclesiástica de suas missões havia sido transferida para os clérigos do Hábito de São Pedro, como ordenaram os documentos oficiais expedidos para os representantes da monarquia em diferentes capitanias ${ }^{51}$. D. Francisco Xavier Aranha, governador da diocese de Pernambuco, elevou a redução da Ibiapaba em freguesia "para que daqui em diante fique do padroado e proteção Real". ${ }^{52}$ Já em 1759, seguindo a cronologia de promoções urbanas adquiridas pela missão da Ibiapaba, o núcleo de índios é convertido em município com seu pelourinho e casa de câmara e cadeia, recebendo a nomeação de Vila Viçosa Real.

Esquematizamos a localização das missões religiosas, com suas respectivas ordens, através da Figura 1 e, portanto, algumas considerações podem ser elencadas: a primeira diz respeito a maior concentração de aldeamentos nas proximidades da praia. Seguindo para o interior do Nordeste, perceberemos que as reduções missioneiras foram pontuais e distantes léguas e léguas uma das outras, o que confere dispersão à urbanização daquele território, se considerarmos esta específica rede urbana. Em áreas de litígio, como as margens médias do rio São Francisco, também chamada de sertão dos Rodelas, encontramos povoações mais adensadas entre si; contudo essa realidade constitui-se um fato único, diante das centenas de comunidades que "salpicaram" o território criadas para a conversão do indígena sertanejo.

Enquanto o sertão das capitanias do Norte era paulatinamente povoado por imensos currais e fazendas de gado, quase que paralelamente os aldeamentos missioneiros surgiram para pacificação e doutrinação dos Tapuias. A Coroa via com bons olhos essa simbiose entre "reses" e "almas". De fato, seriam elementos indispensáveis para seus planos geopolíticos de avanço territorial, para o Oeste. No entanto, esses ideais seriam alcançados através da oficialização de determinados

5o LEITE, Serafim, op. cit., t. III, p. 63-64.

51 Cf. Carta do arcebispo da Bahia para Thomé Joaquim da C. Corte Real, em que se refere especialmente à reforma dos jesuítas e aos provimentos das vigararias do sertão em padres do Hábito de S. Pedro. In: AHU_ACL_CU_BAHIA, cx. 22, d. 4,115 (documentos avulsos).

52 Ordem para a criação das Villas e Vigararias de Índios. Arquivo da matriz de Viçosa, livro de registro n. 2. Revista do Instituto do Ceará, Fortaleza, 1929-1930, p. 34, -349 . 
núcleos urbanos já existentes, ou melhor, a Metrópole lusa deveria reconhecer oficialmente certas povoações, em um primeiro instante, por criar freguesias, depois, se fosse do seu interesse, elevar certas aglomerações ao foro de vila.

As paróquias, chamadas metaforicamente de "as chaves do sertão" pelo padre oratoriano João Duarte da Costa ${ }^{53}$, haviam sido estabelecidas, segundo Murillo Marx, por toda a colônia com o intuito de cumprir o âmbito:

Não era somente o acesso garantido então à desejada e necessária assistência religiosa que se obtinha, mas também o reconhecimento da comunidade de fato e de direito perante a Igreja oficial, portanto perante o próprio Estado. Não era apenas o acesso ao batismo mais próximo, ao casamento mais fácil, ao amparo dos enfermos, aos sacramentos na morte, mas também a garantia do registro de nascimento, de matrimônio, de óbito, registro oficial, com todas as implicações jurídicas e sociais. [...] era também o usufruto da formalidade civil com todo o direito e a segurança que pudesse propiciar ${ }^{54}$

Temos notícia de freguesias instituídas no interior nordestino no final do século XVII, entre essas: Nossa Senhora da Conceição do Cabrobó (criada por volta de 1675) ${ }^{55}$; Santo Antônio da Jacobina (1677); Nossa Senhora da Montanha de Arorobá (1692), antes havia sido missão religiosa dos padres oratorianos; Nossa Senhora da Vitória (1697), futura cidade pombalina de Oeiras do Piauí; e São Francisco da Barra do Rio Grande do Sul (1697). Os critérios considerados pelas autoridades envolveram tanto o remédio para problemas de cunho espiritual quanto temporal. Em miúdos, priorizaram a fixação do homem em sólidas povoações, reduzir o poder fundiário dos mandatários do sertão, a redução das injustiças praticadas entre os moradores e aumento dos rendimentos da fazenda Real, adquiridos por intermédio dos dízimos. De fato, a Coroa procurou reunir a "população dispersa pelos campos” para submetê-la a

53 LIMA, Ebion. As missões oratorianas no Brasil: informação sobre as missões oratorianas no Nordeste. Revista do Instituto Histórico e Geográfico Brasileiro. Rio de Janeiro: IHGB, n. 323. abr./jun., 1979. p. 69-118.

54. MARX, Murillo, op. cit., p. 18-19.

55 Entre parêntesis a provável data de fundação da paróquia. 
seu controle religioso, fiscal, político e administrativo ${ }^{56}$. Assim nos deixa a par o bispo de Pernambuco, d. Francisco de Lima, ao recomendar, em 1697, o desmembramento da gigantesca paróquia de Cabrobó em duas novas: Nossa Senhora da Vitória e São Francisco da Barra do Rio Grande do Sul:

e que daqui por diante, ainda poderá ser maiz util com o intento q' tem de povoarem aquellas terraz, reduziondoas a Collonias, e Povoações, sendo este o meyo, não só de se segurarem aquelles Certoens com estas defenças, mas tambem o de poder lucrar grandez conviniençias a fazenda de V. Mag. ${ }^{\text {de }}$ nos dizimos que se podem tirar da Cultura dellaz[...] e porque V. Mag. ${ }^{\text {de }}$ está obrigado a concorrer com todos os meyos para que os seuz Vassalos tenhão o pasto espiritual por mayores que sejão as distanciaz em que vivão [...] como por não haver modo de justiça naquellas partes; que será rezão se ordene que de sinco em sinco legoas, haia[sic.] um Juiz ordinário com a jurisdição de tirar devaças, tomar as denunciações, e querellaz que nos delictos que aly se fizerem e remetellas por treslado ao Ouvidor geral de Pernambuco, ou ao Ouvidor da Comarca da Bahia $^{57}$

O número de paróquias sertanejas, criadas ao longo do reinado de d. João V, aumentou consideravelmente. No total, foram estabelecidas 27 sedes $^{58}$ de igrejas matrizes no interior do Nordeste, como clara resposta à política urbanizadora joanina. Outra alusão, acerca deste

56 REIS FILHO, Nestor Goulart. Contribuição ao estudo da evolução urbana do Brasil (I50o/I720). $2^{\text {a }}$ ed. São Paulo: Pini, 200o, p. 112.

57 ENNES, Ernesto, op. cit., p. 349-351.

58 Capitania do Maranhão: Nossa Senhora da Conceição e São José das Aldeias Altas (1741) e São Bento das Balças dos Pastos Bons (1741); Capitania do Piauí: Santo Antônio do Surubim (1723); Nossa Senhora do Carmo de Pircuruca (1723); Nossa Senhora do Livramento do Parnaguá (1723); Santo Antônio do Gurguéia (1723); Nossa Senhora da Conceição dos Oroazes (1740); Nossa Senhora do Desterro (1742); Capitania do Ceará: Nossa Senhora do Rosário das Russas (1713); Nossa Senhora da Espectação do Icó (1715)*; São José dos Cariris Novos (1746); Nossa Senhora da Conceição do Riacho do Sangue (1748); Santa Cruz do Aracati (1748); Nossa Senhora da Cruz dos Milagres (1748); Capitania do Rio Grande: São João Batista do Açú (1726); Gloriosa Sant'Ana do Seridó (1748); Capitania da Paraíba: Nossa Senhora dos Milagres da Ribeira do Cariri (1750); Capitania de Pernambuco: Bom Jesus dos Aflitos (1734); Capitania das Alagoas: Nossa Senhora do Ó do rio São Francisco (1714); Capitania de Sergipe Del Rey: Nossa Senhora do Campo do Rio Real (1718); Capitania da Bahia: Santo Antônio do Pambu (1714); Nossa Senhora do Nazaré de Itapicuru de Cima (1718); São João Batista do Jeremoabo (1718); Santíssimo Sacramento do Rio de Contas (1718); São José da Barra do Sento Sé (1719); Livra- 
salto numérico, deve-se à publicação, em 1707, por d. Sebastião Monteiro da Vide, das Constituições Primeiras do Arcebispado da Bahia ${ }^{59}$, normas rigorosas, atentas à uniformidade dogmática, clareza dos ritos e à dilatação da fé católica em lugares povoados, como ordenou o título 687, do livro quarto: "e se edifique [a sede da paróquia] em lugar povoado, onde estiver o maior numero de fregueses". ${ }^{60}$

Já no reinado de d. José I, com apoio direto do conde de Oeiras (futuro marquês de Pombal), verificamos que a rede eclesiástica de freguesias alcançou consideráveis índices [ver Figura 2]. Muito se deve às reformas políticas e sociais pombalinas para essa multiplicação de igrejas matrizes nos sertões do Norte. Pois, como consequência das leis de liberdade ao indígena (6 e 7 de junho de 1755 e o alvará de 8 de maio de 1758) e, principalmente, o Diretório dos Índios, dezenas de aldeamentos missioneiros, espalhados por todas as partes da colônia, foram convertidos, a priori, em lugar de índios com o título de paróquia. $\mathrm{Na}$ capitania do Ceará, por exemplo, o bispo de Pernambuco, d. Francisco Xavier Aranha, recomendou para aquelas missões religiosas que não haviam sido transformadas em vilas, "sejam por nós erectas em Vigarias [sic.] que fazemos interinamente servir por clérigos seculares, até segunda resolução". ${ }^{61}$

Ao contrário do que ocorreu com os períodos joanino e pombalino, durante a administração real de d. Maria I e d. João VI averiguamos uma redução na quantidade de freguesias fundadas no sertão nordestino. Entre 1777-1808 foram instituídas treze paróquias, enquanto que doze sedes de igrejas matrizes surgiram após a chegada da família real ao Brasil e o fim do antigo regime colonial (1822). Para entendermos o porquê dessa diminuição de índices, com nítida repercussão na urbanização daquele território, recorremos a Riolando Azzi quando nos aponta que, a partir da segunda metade do século XVIII, a subordinação do clero aos direitos reais se tornou mais patente ${ }^{62}$.

mento de Nossa Senhora do Rio de Contas (1724); Santo Antônio do Urubu de Cima (1748). Entre parêntesis a data de fundação; já em asterisco a data é imprecisa.

59 VIDE, Sebastião Monteiro da. Constituições primeiras do arcebispado da Bahia, feitas e ordenadas pelo ilustríssimo e reverendíssimo d. Sebastião Monteiro da Vide. Brasília: Senado Federal, Conselho Editorial, 2011.

6o Idem, ibidem, p. $25^{2}$.

61 Ordem para a criação das Villas e Vigararias de Índios, op. cit., p. 346.

62 AZZI, Riolando. A instituição eclesiástica durante a primeira época colonial. In: HORNAERT, Eduardo. História da Igreja no Brasil: ensaio de interpretação a partir do povo (primeira época, Período Colonial). $5^{\text {a }}$ ed. Petrópolis: Rio de Janeiro, 2008, p. 181 . 
A pecuária e povoações com a qualificação de freguesia atraíram o colono português (principalmente das províncias do Minho, Trás os Montes e Douro) ao interior, região onde seria mais fácil encontrar uma fatia de terra devoluta ou ainda por descobrir. O crescimento demográfico provocou uma série de problemas sociais: assaltos às fazendas de gado, litígio entre famílias rivais, assassinatos, apropriação indevida das sesmarias de outrem, entre outros aspectos. A demanda por justiça tornou-se a base para a formatação da rede civil de vilas nos rincões do Nordeste. Fato observado desde a criação da primeira municipalidade (Mocha, 1711) até o final do colonialismo (1822).

Entre as primeiras vilas criadas- Mocha $(1711)^{63}$; Jacobina (1722); Livramento de Nossa Senhora do Rio de Contas (1724); Inhambupe (1727); Água Fria (1727); Itapicuru (1727) e Icó (1736); Rio de Contas (1745) e Urubu (1748) -, a boa administração da justiça, para sossego e "quietação dos povos", foi assunto largamente pautado nas correspondências entre as autoridades da colônia e os funcionários da monarquia, locados no Conselho Ultramarino. A paróquia piauiense de Nossa Senhora da Vitória recebeu o status de vila em 1711, instalada somente em 1717, passando a ser chamada de vila da Mocha, em homenagem ao riacho que serpenteia o seu espaço urbano. Para a instituição de Mocha, d. João V ordenou o ouvidor geral do Maranhão, Euzébyo Capelli, que "no lugar aonde está a Igreja matriz crieis huma Villa com Senado da Câmara [...] para se administrar a justiça, e se evitarem os delictos que nella se cometem por falta de castigos". ${ }^{64}$ Idem para a vila do Icó, fundada em 1736 na capitania do Ceará:

O ouvidor geral da capitania do Ceará Pedro Cardoso de Novaes Pereira me escreveo a carta de q' com esta remeto a copia para fazer presente a v. mag. ${ }^{\text {de }}$ a neceçidade q' ha de mandar criar de novo huma villa naquella capitania no lugar q' o chamão o Icó, aonde está a igreja matriz do destricto, e não só me paresse justo q' haja para a admenistração da justiça mas he perciso p. ${ }^{\text {a }}$ a quietassão dos povos, pella distancia de oitenta legoas q' fica a villa de Achirás, de q' he termo. ${ }^{65}$

63 Entre parêntesis estão os anos de fundação das respectivas vilas.

64. O Livro grosso do Maranhão. Anais da Biblioteca Nacional do Rio de Janeiro. Rio de Janeiro: Divisão de Obras Raras e Publicações, 1948, v. LXVII, $2^{a}$ parte, p. 104.

65 AHU_ACL_CU_O15, cx. 48, d. 4254 . 
A dispersão dos núcleos urbanos sertanejos e os descômodos de viverem isolados, pois "quando lhes chegam os despachos vem tam tarde que não servindo para o remedeo das queixas trazem sempre a ruína" ${ }^{66}$, foram alguns condicionantes incluídos na carta régia de 19 de junho de 1761, passada ao governador da recém criada capitania de São José do Piauí, no que diz respeito à concessão do título de vila às seis freguesias existentes naquele território. Contemporâneo à citada carta régia é a publicação, em 1758, do Diretório dos Índios. O reflexo dessa nova lei nos sertões do Nordeste se deu pela conversão de treze aldeamentos missioneiros em municipalidades, distribuídas desde o Maranhão até a capitania da Bahia. Nas novas vilas de índios, os congregados ficaram "subgeitos ao estabelecido sistema de viver, avillados, subordinados as Leis com seus legítimos principais, e superiores havendo em cada villa hum director, hum pároco Branco e Câmara composta de juízes ordinários, e Vereadores, em parte Índios, e em parte Brancos". ${ }^{67}$ Tal sistema de viver buscou homogeneizar a civilização dos nativos através da boa administração da justiça, agricultura, do comércio e do contato com portugueses. Ao invés de doutrinar os neófitos, como faziam os missionários, o ideal seria civilizá-los ${ }^{68}$.

O ápice da urbanização dos "Certoens do Norte" ocorreu em 1761, com a elevação da vila da Mocha em cidade, agora chamada de Oeiras em homenagem a Sebastião José de Carvalho e Melo, o conde de Oeiras. $\mathrm{O}$ ato de fundar uma cidade na colônia não era tarefa simples, pois nem todas as vilas tinham suportes quantitativos e qualitativos para merecer o título. Portanto, o jogo de escolhas se concentrou nas mãos da Coroa e seus representantes diretos. Os debates entre as autoridades coloniais e ultramarinas nos dão interessantes pistas sobre quais questionamentos foram vigorados ou negados para a eleição da futura cidade.

Analisando a voo de pássaro a situação da vila da Mocha no contexto econômico e geopolítico da colônia, entenderemos alguns porquês de sua eleição. No final dos Seiscentos, o território eclesiástico da freguesia de Nossa Senhora da Vitória contou com 129 fazendas de gado distribuídas

66 AHU_ACL_CU_o18, cx. o8, d. 463.

67 AHU_ACL_CU_o14, cx.41, d. 2853.

68 Para Maria Helena Flexor, civilizar os índios significava fazê-los vestirem-se, ter uma vida espiritual e temporal semelhante aos portugueses, bem como ter acesso ao comércio e agricultura. Isto equivale dizer, impor os valores dos brancos: vida sedendária, moral, ambição, acúmulo de bens, unidade familiar. Cf. FLEXOR, Maria Helena. Os núcleos urbanos planejados do séculos XVIII: Porto Seguro e São Paulo. Salvador: Centro de Estudos Baianos da UFBA, 1989, p. 10. 
ao longo dos rios Parnaíba, Canindé, Piauí, Itaim, entre outros ${ }^{69}$. Com o avanço da pecuária no mercado colonial brasileiro, basicamente como fonte de abastecimento do litoral e das áreas mineradoras (aqui também se enquadram as minas do Goiás), o número das herdades aumentou, em 1730, para um total de quatrocentos exemplares ${ }^{70}$. Entre os anos de 1752-1754 foram arrematados os dízimos referentes às paróquias do Piauí. Mocha depositou nos cofres da Fazenda Real o considerável montante de 52.900\$000 réis, desses cerca de $7.127 \$ 000$ réis derivaram do gado criado em seu termo ${ }^{71}$.

Em 1758, os funcionários do rei definiram os contornos territoriais da capitania de São José do Piauí. Para a sua implantação, o secretário da Marinha e Ultramar, Tomé Joaquim da Costa Corte Real, e o capitão general do Pará, Francisco Xavier de Mendonça Furtado, notaram a importância do Piauí para a "subsistencia da Bahia e Pernambuco e ao muito que importa nas presentes circunstancias fortificarnos nos centros dos Certoens do Brazil depois que se manifestou que por elles pretendiam arruinar e dominar aquelle estado os Religiosos Jesuítas". ${ }^{72}$ Abastecimento e vigilância aos domínios fundiários dos inacianos localizados no Piauí (sequestrados de fato após a completa extradição da Companhia de Jesus do Brasil, em 1759) corroboraram às iniciativas dos administradores coloniais para a instalação da capitania. O centro de poder e controle das diversas instâncias do Piauí estaria em Mocha, ou melhor, em Oeiras [Figura 3].

Assim como ocorreu com a rede de freguesias, a quantidade de vilas criadas no sertão nordestino diminuiu entre o final da era pombalina (1777) e à chegada da família real ao Brasil (1808). Ao todo foram criados oito núcleos urbanos: quatro no Ceará, agora capitania independente e desmembrada da de Pernambuco, em 1799; uma vila no Rio Grande do Norte; duas na Paraíba e uma na Bahia. A toponímia das vilas eretas valorizou ou adulou a figura do monarca regente como centro da política e vida colonial: temos uma vila Nova da Rainha, vila Nova del Rey e vila Nova do Príncipe.

A criação de gado, como explanado anteriormente, sofreu uma séria queda de produção e comercialização a partir do final do século XVIII. Tal redução econômica resultou em uma série de debates entre as câmaras das vilas sertanejas a buscar melhorias ao comércio local e

69 ENNES, Ernesto, op. cit., p. 368.

70 MOTT, Luiz R. B. Piauí colonial: população, economia, sociedade. Teresina: Projeto Petrônio Portella, 1985, p. 57 .

71 AHU_ACL_CU_ol6, cx. 6, d. 388 .

72 AHU_ACL_CU_ol6, cx. 5, d. 359 . 
regional. É o caso, por exemplo, do senado da cidade de Oeiras do Piauí que, desde meados do século XVIII e junto ao governo da capitania do Maranhão, cogitavam a mudança da capital para as margens do rio Parnaíba ou transferência direta do título de cidade para a comerciante vila de Parnaíba, localizada na foz do rio sobredito ${ }^{73}$.

Levando em consideração a urbanização em uma escala maior, a das capitanias do Norte, entre 1808-1822 foram municipalizadas doze povoações: quatro na capitania do Maranhão; duas no Ceará; uma na Paraíba; três na capitania de Pernambuco e duas na capitania da Bahia. No Piauí nenhuma vila havia sido instituída desde 1761, sendo repercussão, quiçá, da nova realidade econômica daqueles sertões. A partir de 1813, segundo Joaquim Veríssimo Serrão, a Coroa desenvolveu cada vez mais a organização judicial no Brasil. Para isso aproveitou a criação simultânea de vilas, correspondendo aos pedidos das câmaras e ao sentir da população residente ${ }^{74}$. Queria d. João VI que seus vassalos, através dos novos municípios, gozassem do sossego e bem público, resultantes da pronta e bem atendida administração da justiça ${ }^{75}$. Assim, surgiram no interior do Nordeste os cargos de juiz de fora, em 1810 e 1811 respectivamente, para as vilas de Rio de Contas (BA) e Caxias das Aldeias Altas (MA). Na capitania de Pernambuco, a imensa comarca de Olinda foi desanexada em 1810, sendo oficializada a comarca do Sertão, com sede na recém-inaugurada vila de Flores do Pajeú ${ }^{76}$.

Este breve panorama político, econômico, social e religioso tentou introduzir algumas questões da urbanização encerrada no interior das capitanias do Norte, lacunas existem e persistirão. Consideramos que não se tratou de um fenômeno simples, pelo contrário, a rede de relações e os fluxos fundamentados pelo gado elaboraram uma intricada rede de caminhos, pousos e fazendas, viabilizando o mercado interno voltado ao abastecimento dos principais centros urbanos da colônia (São Luís, Recife, Olinda, Salvador, Rio de Janeiro e arraiais mineiros). A ascensão da teia paroquial, relativamente densa em certas partes da região, e dispersa em outras, oficializou o povoamento dos vastos sertões, sendo

73 AHU_ACL_CU_o16, cx. 24, d. 1240.

74. SERRÃO, Joaquim Veríssimo. História de Portugal. (A instauração do liberalismo: 1807 - 1832). Lisboa: Editora Verbo, 1983, v. VII, p. 167 .

75 Idem, ibidem.

76 “Alvará com força de Lei, pelo qual Vossa Alteza Real ha por bem Crear a nova Comarca do Sertão de Pernambuco, desanexando da antiga algumas Villas, e Julgados; e erigir em Villas as Povoações do Pilão Arcado, e de Flores na Ribeira do Pajahú; na forma acima exposta”. Disponível em: <http://archive.org >. Acesso em: 21 set. 2012. 
o preâmbulo da teia civil de vilas, cujas trocas entre si e com o território organizaram um sistema com funções hierárquicas determinadas no ultramar, nos governos das capitanias e nas câmaras das vilas sertanejas.

\section{Sobre o autor}

\section{Esdras Arraes}

Arquiteto e urbanista, possui graduação em Arquitetura e Urbanismo na Universidade Federal de Pernambuco(UFPE) e mestrado na Faculdade de Arquitetura e Urbanismo da Universidade de São Paulo (USP). Atualmente, é doutorando na mesma instituição. E-mail: esdras_arraes@yahoo.com.br

\section{Agradecimento}

Agradeço à Fundação de Amparo à Pesquisa do Estado de São Paulo (Fapesp) pelo apoio concedido à realização dessa pesquisa. 


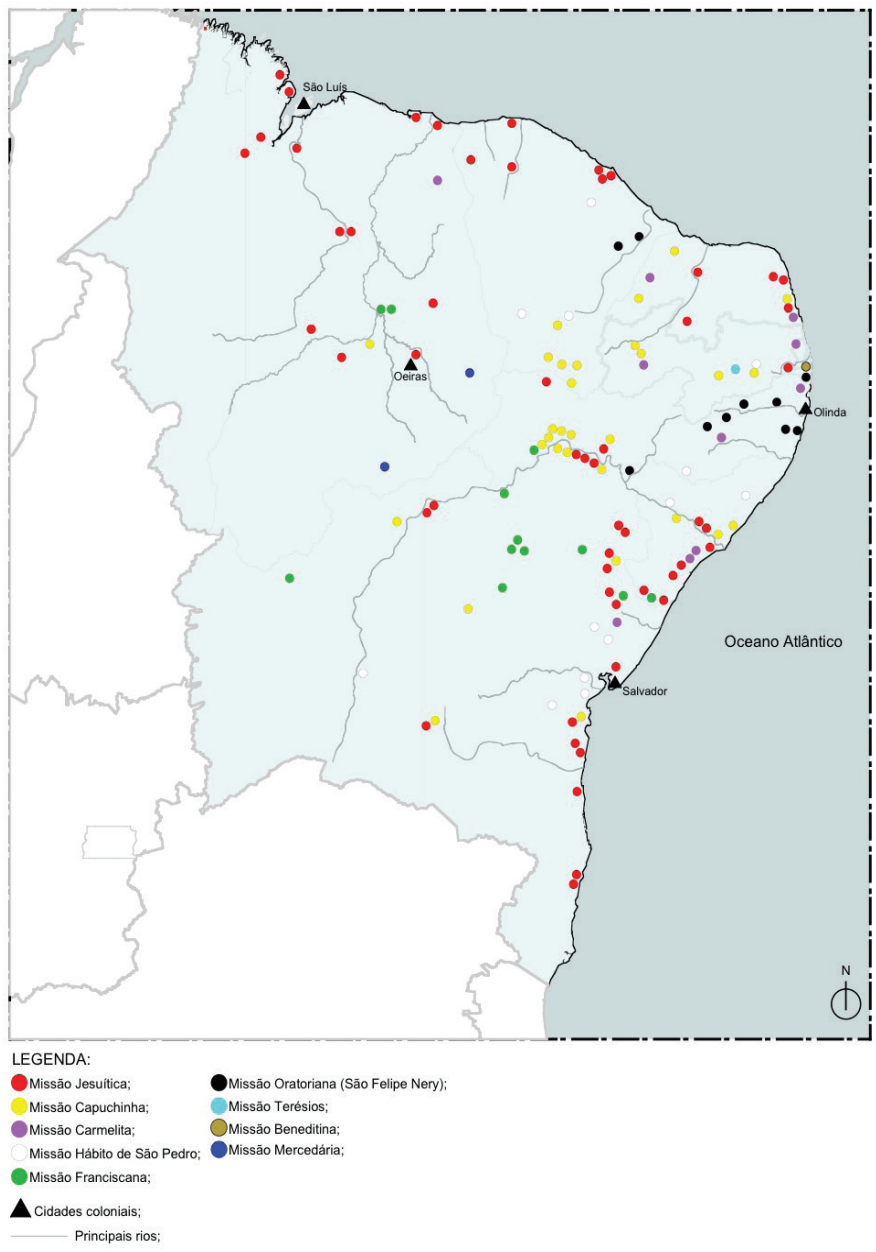

Figura 01: Aldeamentos missioneiros no Nordeste fundados entre 1549 - 1822. Desenho do autor sobre informações encontradas em ABREU, Caspistrano. Capítulos de história colonial, 1500 - 1800. 7 ed. São Paulo: Publifolha, 2000. p. 194 - 197; PACHECO DE OLIVEIRA, João [org.]. A presença indígena no Nordeste: processo de territorialização, modos de reconhecimento e regimes de memória. Rio de Janeiro: Contra Capa, 2011. p. 690 - 707; e manuscritos encontrados no Projeto Resgate Barão do Rio Branco. 


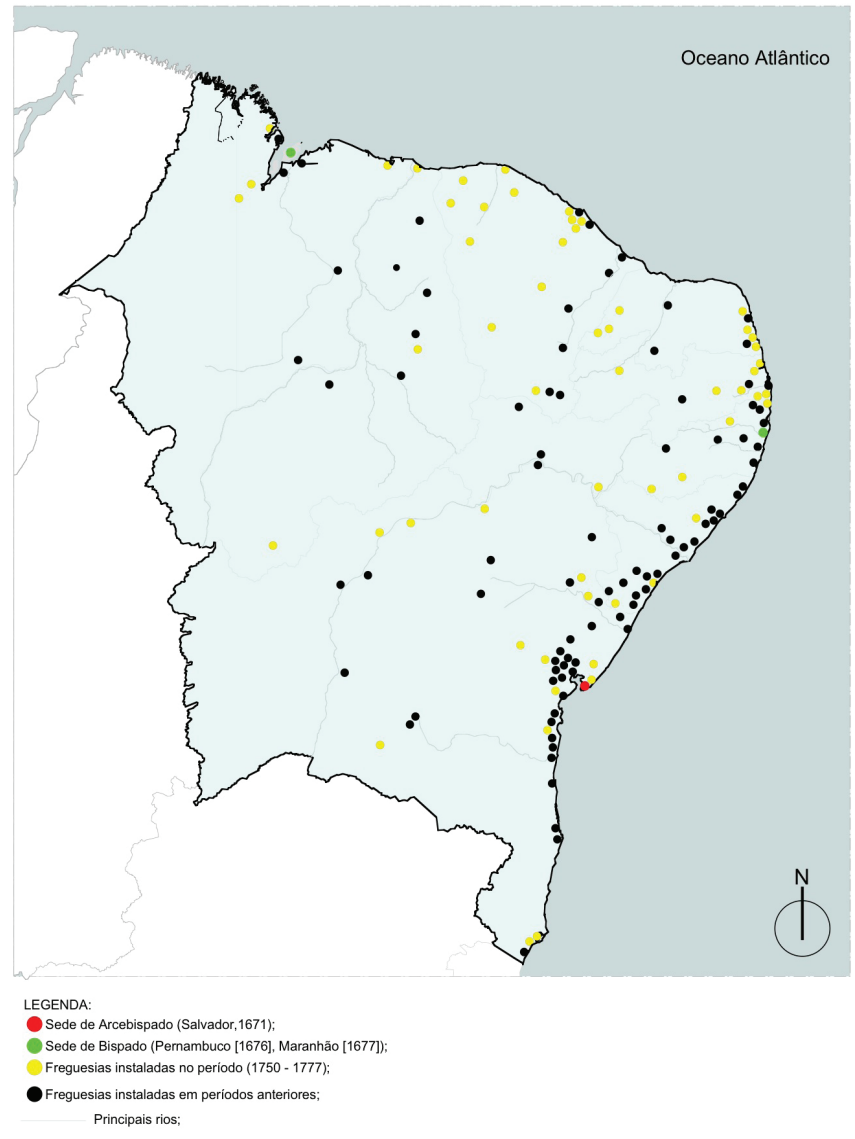

Figura 02: Freguesias instituídas no período pombalino, 1750 - 1777. Desenho do autor sobre informações encontradas nos manuscritos do Projeto Resgate Barão do Rio Branco e na Enciclopédia dos Municípios Brasileiros. 


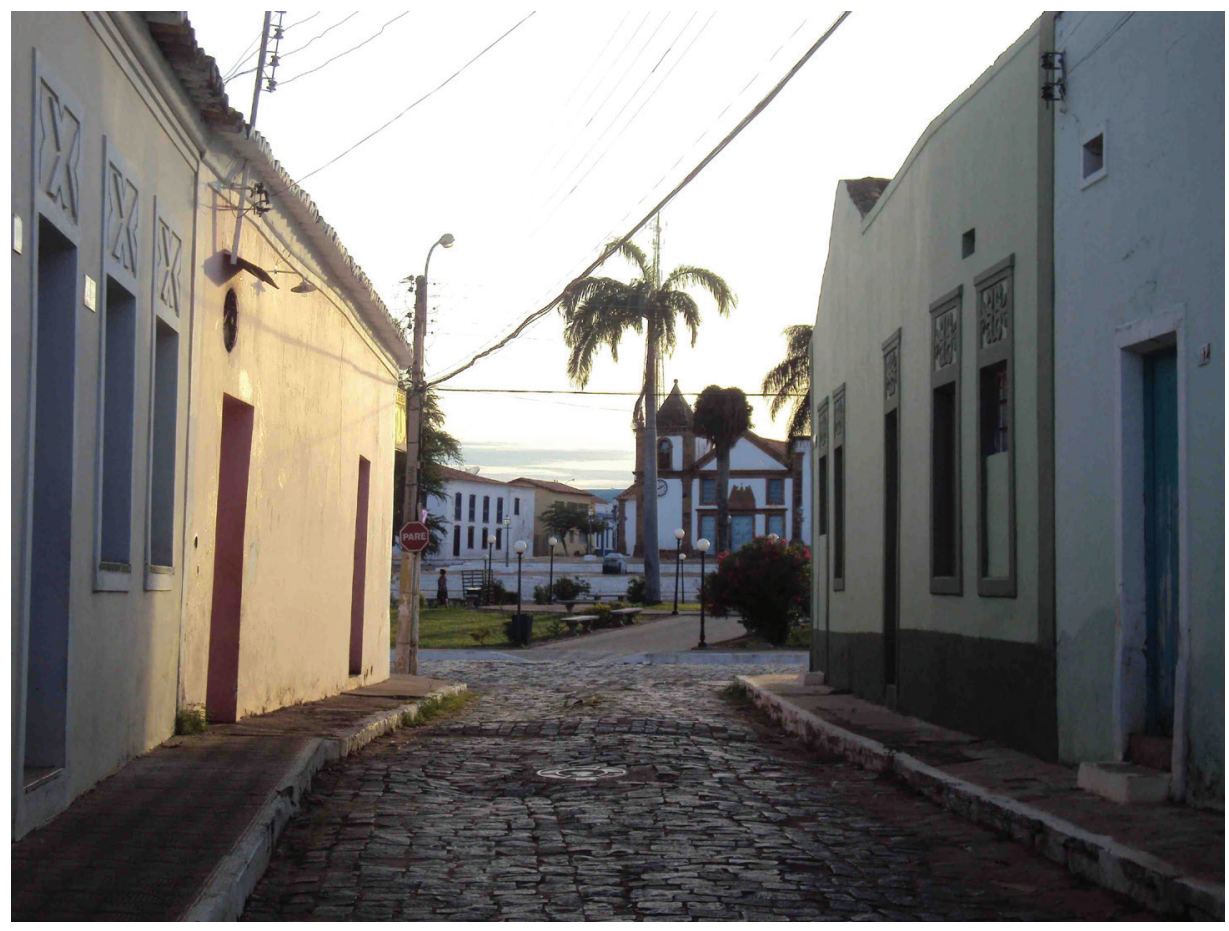

Figura 03: Cidade de Oeiras do Piauí. Foto do autor, 2010. 
